\title{
In reply: Eye taping and chlorhexidine exposure: caution when interpreting scarce evidence
}

\author{
Cara Reimer, MD, MSc, FRCPC
}

Received: 23 October 2017/Revised: 20 November 2017/ Accepted: 20 November 2017/Published online: 27 November 2017

(C) Canadian Anesthesiologists' Society 2017

\section{To the Editor,}

Dr. Shive raises some important points ${ }^{1}$ in response to my original letter ${ }^{2}$ regarding eye taping and chlorhexidine exposure. The additional issues of adequacy of adhesive application and the effects of gravity and pooling need to be considered in this discussion. To prevent liquid from entering the eye, the tape must cover the entirety of the closed eye and be applied to ensure that the edges are not, or do not become, rolled or unadhesed. In the case reports to which Dr. Shive referred, ${ }^{3}$ the adequacy of Tegaderm ${ }^{\mathrm{TM}}$ (3M, St. Paul, MN, USA) application was not mentioned, but it was hypothesized that the dressing may not have "remained fully adherent" during these long cases. Accordingly, I undertook a subsequent experiment in which chlorhexidine was applied vertically to the edges of both fully and partially adhesed (i.e., rolled back)

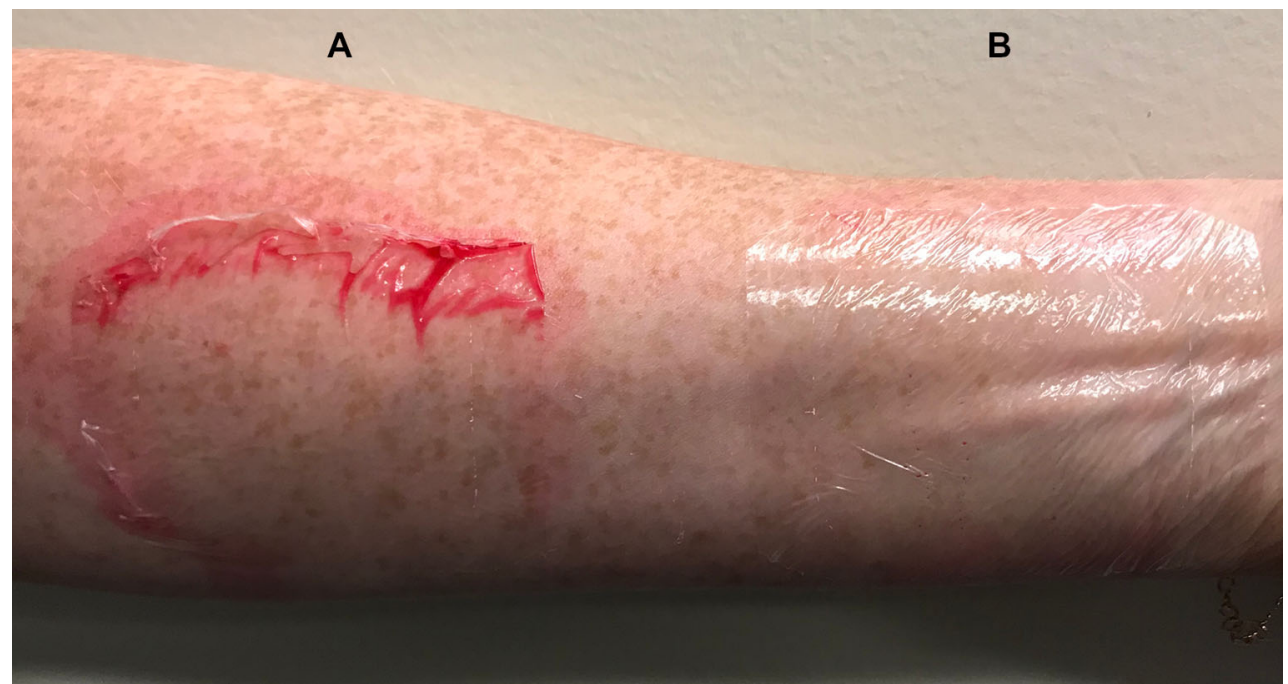

Figure Movement of liquid under 3M Tegaderm after application of $3 \mathrm{M}$ Soluprep $2 \% \mathrm{w} / \mathrm{v}$ chlorhexidine gluconate and $70 \% \mathrm{v} / \mathrm{v}$ isopropyl alcohol (3M, St. Paul, MN, USA) to superior edge of a partially adhesed (A) and fully adhesed (B) dressing. There was some minor movement of chlorhexidine under the fully adhesed dressing but substantially more under the partially adhesed dressing

C. Reimer, MD, MSc, FRCPC ( $\square)$

Kingston General Hospital, Queen's University, Kingston, ON,

Canada

e-mail: reimerc@kgh.kari.net 
Tegaderm. There was flow of the liquid underneath both dressings. However, there was substantially more chlorhexidine underneath the partially adhesed product (see Figure).

As the literature often reminds us, and Dr. Shive's letter echoes, there clearly is no substitute for the vigilance of the anesthesiologist. ${ }^{4}$ My routine practice for breast, chest, and head and neck cases is to pay strict attention during surgical preparation, even after Tegaderm placement. For craniotomies and prone neck cases I also hold gauze sponges lateral to the dressed eyes to catch any drips of the chlorhexidine that may, by gravity, come into the eye or forehead area. This practice, accompanied by frequent checks during the case, has (thus far) prevented eye injuries in my patients.

Admittedly, there is no body of evidence supporting routine eye taping in deeply sedated or anesthetized patients outside the operating room who are exposed to chlorhexidine (e.g., intensive care during line placement). This discussion, however, raises the question why these patients should be treated any differently than a patient undergoing sterile preparation to the neck, shoulder, or upper chest in the operating room. In my mind, this scenario appears to be one of the easier risk/benefit conundrums with which we are faced in practice - i.e., the risk of taping is low, and the potential for life-altering injury to the eye if chlorhexidine makes contact is high. Perhaps this discourse will lead others to reconsider eye protection in domains outside the operating room and will bring some attention to preventing a potentially catastrophic complication.

Conflicts of interest None declared.

Editorial responsibility This submission was handled by Dr. Hilary P. Grocott, Editor-in-Chief, Canadian Journal of Anesthesia.

\section{References}

1. Shive M. Eye taping and chlorhexidine exposure: caution when interpreting scarce evidence. Can J Anesth 2018; 65: this issue. http://doi.org/10.1007/s12630-017-1027-5

2. Reimer $C$. Eye taping during anesthesia and chlorhexidine exposure. Can J Anesth 2017; 64: 1159-60.

3. Bever GJ, Brodie FL, Hwang DG. Corneal injury from presurgical chlorhexidine skin preparation. World Neurosurg 2016; 96: 610.e1-4.

4. Rall M, Gaba D, Howard SK, Dieckmann P. Human performance and patient safety. In: Miller RD, editor. Miller's Anesthesia. Philadelphia, PA: Churchill Livingstone Elsevier; 2010. p. 93-149. 